\title{
МЕТОДИКА АКТИВИЗАЦИИ ИННОВАЦИОННОЙ ДЕЯТЕЛЬНОСТИ В ВЫСШЕМ УЧЕБНОМ ЗАВЕДЕНИИ
}

\author{
(c) 2020 Лямин Борис Михайлович \\ ассистент \\ Санкт-Петербургский политехнический университет Петра Великого, Россия, Санкт-Петербург \\ E-mail: lyamin.bm@gmail.com \\ (c) 2020 Фурин Александр Геннадьевич \\ кандидат экономических наук, доцент \\ Поволжский государственный технологический университет, Респ. Марий Эл, Йошкар-Ола \\ E-mail: furin_ag@mail.ru
}

В статье проведен анализ потенциала коммерциализации результатов инновационной деятельности высшего учебного заведения. На основе проведенного анализа предложена методика активизации инновационной деятельности в высшем учебном заведении, основанная на формировании научно-исследовательского коллектива на основе компетентностного подхода под конкретную научную задачу. Анализ потенциала коммерциализации результатов инновационной деятельности произведен с использованием нечетко-множественного подхода, что позволило объективно оценить потенциал коммерциализации результата инновационной деятельности высшего учебного заведения, в частности солнцемобиль SOL разработанного командой молодежного конструкторскотехнологического бюро Polytech Solar Team. На основании полученных данных необходимо сформировать методику активизации инновационной деятельности высшего учебного заведения. Предложенная методика позволяет формировать такие научно-исследовательские группы, которые исходя их своих компетенций будут способны решать поставленные перед ними научные задачи, при этом необходимо применять стимулирование инновационной деятельности сформированного коллектива исходя из потребностей участников научно-исследовательского коллектива.

Ключевые слова: инновационная деятельность, стимулирование инновационной деятельности, высшие учебные заведения, нечетко-множественный подход, результаты инновационной деятельности.

Инновационная деятельность высшего учебного заведения рассматривается как одно из главных условий не только совершенствования образовательного процесса в вузе, но и модернизации экономики страны в целом, обновляя и совершенствуя её материально-технический потенциал. При этом, специфика высшего учебного заведения, активно занимающегося инновационной деятельностью, заключается в наличии и совершенствовании инновационной деятельности работников, генерации знаний в различных областях науки, возможных к внедрению в практическое пользование по широкому спектру направлений. Для активизации инновационной деятельности работников необходимо применять особый подход к стимулированию инновационной деятельности, который учитывает вместе с материальным стимулированием профессорско-преподавательского состава, нематериальное стимулирование, а также стиму- лирование, основанное на административном воздействии на работников [3,4,5,6]. В случае эффективного стимулирования инновационной деятельности работников высшего учебного заведения, создаются результаты инновационной деятельности (РИД), соответствующие требованиям, предъявляемым к результатам инновационной деятельности, в которых прописана необходимость их внедрения на предприятия. Таким образом, возникает потребность в коммерциализации результатов инновационной деятельности.

При коммерциализации инноваций возникает ряд проблем, который не позволяет получить планируемый доход в результате реализации инновации на рынок, выделим две основные проблемы [1,2]:

- низкая эффективность применяемых методик оценки рыночной стоимости РИД. В настоящее время не разработан единый уни- 
версальный механизм оценки стоимости РИД, соответственно в каждом отдельном случае оценка производится различными способами, что ведет к определенным издержкам. Предприятия, заинтересованные в изобретении, не могут с высокой долей вероятности оценить уровень прибыли, который они могут получить в результате его внедрения в производство.

- не соответствие характеристик РИД требованиям рынка. Результаты инновационной деятельности формируются в результате работы коллектива исследователей, которые занимаются научной тематикой, которая им интересна, однако, несмотря на научную новизну и уникальность РИД может быть не применим в сложившихся условиях хозяйствования или требовать серьезных инвестиций в изменение работающих процессов [11,13].

Исходя из выявленных проблем, необходимо разработать такой механизм оценки стоимости РИД, который бы позволял потенциальным потребителям РИД понимать какую прибыль они получат от его внедрения, а исследовали генерировали только те РИД, которые имеют высокий потенциал коммерциализации.

Результаты инновационной деятельности характеризуются высокой степенью неопределенности, в связи с этим определить точную стоимость оценки является очень сложной задачей. Поэтому целесообразным видится выделение нечетких интервалов оценки, характеризующихся уровнем уверенности эксперта в сделанных выводах. Следовательно, одним из наиболее подходящих для построения модели оценки потенциала коммерциализации результатов инновационной деятельности является нечеткомножественный подход. Применение данного метода позволит выявить потенциал коммерциализации РИД и возможность его успешной реализации на рынке.

Оценивая стоимость РИД, необходимо либо учитывать только количественные факторы, либо учитывать все факторы, однако это будет вызывать большие затруднения в виду высокой трудоемкости процесса. В связи с этим, можно предложить оценивать потенциал коммерциализации РИД, для того чтобы выявить перспективные разработки для вывода их на рынок и получения прибыли.

Предложенная модель оценки коммерциализации РИД на основе нечетно-множественных классификаторов позволяет учитывать множе- ство факторов, влияющих на РИД, при этом, нивелируя неточности оценки за счет анализа уверенности экспертов [10].

Произведем оценку потенциала коммерциализации разработки команды молодежного конструкторско-технологического бюро Polytech Solar Team, уникальное транспортное средство солнцемобиль SOL (Санкт-Петербургский политехнический университет Петра Великого).

При создании солнцемобиля команда делает акцент на оптимизации расхода энергии, создании выгодной аэродинамической формы кузова автомобиля и уменьшении его веса.

Оценка потенциала коммерциализации проекта состоит из двух основных этапов: подготовительного и этапа оценки (рис. 1).

Оценим показатели внутреннего потенциала РИД. Привлечённая группа экспертов оценила показатели. Результаты оценки представлены в таблице 1 .

На следующем этапе производится распознавание принадлежности значений данных показателей в соответствии со сформированными нечетко-множественными классификаторами. Данные значения принадлежности позволяют определить соответствующие узловые точки нечетких подмножеств. С учетом веса влияния и вектора влияния показателей мы получаем интегральную оценку внутреннего потенциала РИД (табл. 2).

На завершающем этапе распознаем принадлежность интегрального показателя. В данном случае получаем уровень внутреннего потенциала РИД на уровне 27\%, что является допустимым показателем.

Аналогично произведем оценку потенциала субъекта, создавшего результат инновационной деятельности. Привлечённая группа экспертов оценила показатели. Результаты оценки представлены в таблице 3.

Аналогично производится распознавание принадлежности значений данных показателей в соответствии с сформированными нечеткомножественными классификаторами. С учетом веса влияния и вектора влияния показателей получаем интегральную оценку потенциала субъекта РИД (таблица 4).

Проводим распознавание интегрального показателя, потенциал субъекта РИД со значением 72,7\% характеризует высокий потенциал коммерциализации.

Наконец, произведем оценку факторов 


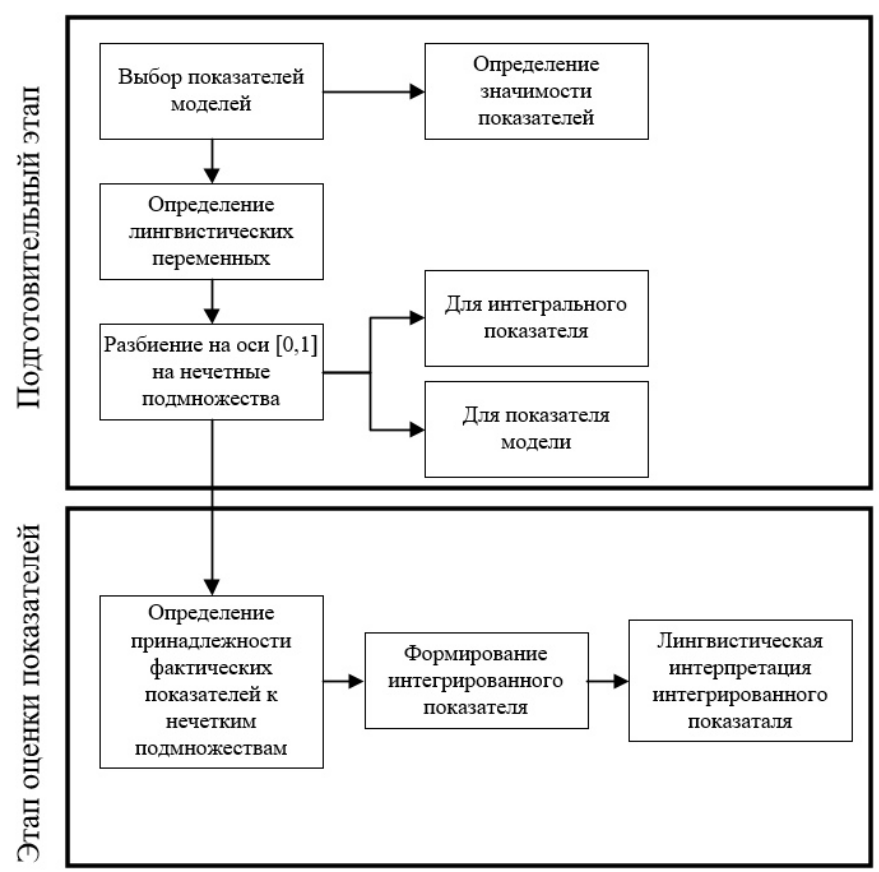

Рисунок 1. Типовой алгоритм построения нечетко-множественных моделей оценки Источник: составлено автором

Таблица 1. Оценка показателей, характеризующих степень влияния внутреннего потенциала РИД на потенциал коммерциализации РИД

\begin{tabular}{|c|c|c|c|c|}
\hline № & \multicolumn{4}{|l|}{ Внутренний потенциал РИД } \\
\hline 1. & \multicolumn{4}{|l|}{ Уникальный характер РИД } \\
\hline 1.1 & Степень уникальности РИД & $\mathrm{F}_{\mathrm{t} / \mathrm{i}-1}$ & 8,5 & балл. \\
\hline 2. & \multicolumn{4}{|l|}{ Время сохранения инновационного ресурса } \\
\hline 2.1 & Период времени в течение которого у РИД не будет аналогов & $\mathrm{F}_{\mathrm{t} / \mathrm{i}-2}$ & 36 & мес \\
\hline 3. & \multicolumn{4}{|c|}{ Необходимость значительного изменения технологии перед внедрением } \\
\hline 3.1 & Период времени необходимый на внедрение в производство & $\mathrm{F}_{\mathrm{t} / \mathrm{i}-3}$ & 280 & дни \\
\hline 3.2 & Количество изменений существующей технологии & $\mathrm{F}_{\mathrm{t} / \mathrm{i}-4}$ & 10 & ед \\
\hline 3.3 & Затраты, понесенные при внедрении РИД & $\mathrm{F}_{\mathrm{t} / \mathrm{i}-5}$ & 50 & $\%$ \\
\hline 4. & \multicolumn{4}{|l|}{ Потенциал сферы применения } \\
\hline 4.1 & Инновационная активность организаций & $\mathrm{F}_{\mathrm{t} / \mathrm{i}-6}$ & 20 & $\%$ \\
\hline 4.2 & $\begin{array}{l}\text { Удельный вес затрат на технологические инновации в общем объеме } \\
\text { отгруженных товаров, выполненных работ, услуг }\end{array}$ & $\mathrm{F}_{\mathrm{t} / \mathrm{i}-7}$ & 18 & $\%$ \\
\hline 5. & \multicolumn{4}{|l|}{ Уровень затрат на создание РИД } \\
\hline 5.1 & Материальные затраты на создание РИД & $\mathrm{F}_{\mathrm{t} / \mathrm{i}-8}$ & 1000 & $\begin{array}{l}\text { тыс. } \\
\text { руб }\end{array}$ \\
\hline 5.2 & Количество персонала, занятого созданием РИД & $\mathrm{F}_{\mathrm{t} / \mathrm{i}-9}$ & 20 & чел \\
\hline
\end{tabular}

Источник: составлено автором 
Таблица 2. Интегральная оценка внутреннего потенциала РИД

\begin{tabular}{|c|c|c|}
\hline o & Показатель & Значение \\
\hline 1. & $\mathrm{~F}_{\mathrm{t} / \mathrm{i}-1}$ & 0,038 \\
\hline 2. & $\mathrm{~F}_{\mathrm{t} / \mathrm{i}-2}$ & 0,02 \\
\hline 3. & $\mathrm{~F}_{\mathrm{t} / \mathrm{i}-3}$ & 0,046 \\
\hline 4. & $\mathrm{~F}_{\mathrm{t} / \mathrm{i}-4}$ & 0,0116 \\
\hline 5. & $\mathrm{~F}_{\mathrm{t} / \mathrm{i}-5}$ & 0,0116 \\
\hline 6. & $\mathrm{~F}_{\mathrm{t} / \mathrm{i}-6}$ & 0,077 \\
\hline 7. & $\mathrm{~F}_{\mathrm{t} / \mathrm{i}-7}$ & 0,049 \\
\hline 8. & $\mathrm{~F}_{\mathrm{t} / \mathrm{i}-8}$ & 0,0075 \\
\hline 9. & $\mathrm{~F}_{\mathrm{t} / \mathrm{i}-9}$ & 0,0075 \\
\hline \multicolumn{2}{|c|}{ Итого } \\
\hline
\end{tabular}

Источник: составлено автором

Таблица 3. Оценка показателей, характеризующих степень влияния потенциала субъекта РИД на потенциал коммерциализации РИД

\begin{tabular}{|c|c|c|c|c|}
\hline № & \multicolumn{4}{|l|}{ Потенциал субъекта РИД } \\
\hline 1. & \multicolumn{4}{|l|}{ Опыт коммерциализации РИД } \\
\hline 1.1 & Количество РИД, успешно реализованных на рынке & $\mathrm{F}_{\mathrm{t} / \mathrm{s}-1}$ & 1 & Ед. \\
\hline 1.2 & Опыт реализации РИД на рынке & $\mathrm{F}_{\mathrm{t} / \mathrm{s}-2}$ & 4 & лет \\
\hline 2. & \multicolumn{4}{|c|}{ Доступность необходимых ресурсов для создания РИД } \\
\hline 2.1 & $\begin{array}{l}\text { Перечень мировых технологий к которым у исследователей есть до- } \\
\text { ступ }\end{array}$ & $\mathrm{F}_{\mathrm{t} / \mathrm{s}-3}$ & 24 & ед \\
\hline 2.2 & $\begin{array}{l}\text { Количество предметных баз данных, которые исследователи могут } \\
\text { использовать }\end{array}$ & $\mathrm{F}_{\mathrm{t} / \mathrm{s}-4}$ & 40 & ед \\
\hline 2.3 & $\begin{array}{l}\text { Достаточность современного оборудования, (лабораторий) необходи- } \\
\text { мого для создания РИД }\end{array}$ & $\mathrm{F}_{\mathrm{t} / \mathrm{s}-5}$ & 75 & $\%$ \\
\hline 3. & \multicolumn{4}{|l|}{ Наличие ресурсов для коммерциализации РИД } \\
\hline 3.1 & Достаточность ресурсов необходимых для коммерциализации РИД & $\mathrm{F}_{\mathrm{t} / \mathrm{s}-6}$ & 34 & $\%$ \\
\hline 4. & \multicolumn{4}{|l|}{ Технологические возможности предприятия } \\
\hline 4.1 & Достаточность технологических площадок для производства РИД & $\mathrm{F}_{\mathrm{t} / \mathrm{s}-7}$ & 95 & $\%$ \\
\hline 4.2 & Достаточность персонала требуемой квалификации & $\mathrm{F}_{\mathrm{t} / \mathrm{s}-8}$ & 78 & $\%$ \\
\hline 5. & \multicolumn{4}{|l|}{ Уровень правовой защиты РИД } \\
\hline 5.1 & $\begin{array}{l}\text { Количество охранных документов на РИД (патенты, лицензии, свиде- } \\
\text { тельства и т.д.) }\end{array}$ & $\mathrm{F}_{\mathrm{t} / \mathrm{s}-9}$ & 1 & Ед. \\
\hline
\end{tabular}

Источник: составлено автором

Таблица 4. Интегральная оценка потенциала субъекта РИД

\begin{tabular}{|c|c|c|}
\hline № & Показатель & Значение \\
\hline 1. & $\mathrm{~F}_{\mathrm{t} / \mathrm{s}-1}$ & 0,153 \\
\hline 2. & $\mathrm{~F}_{\mathrm{t} / \mathrm{s}-2}$ & 0,119 \\
\hline 3. & $\mathrm{~F}_{\mathrm{t} / \mathrm{s}-3}$ & 0,024 \\
\hline 4. & $\mathrm{~F}_{\mathrm{t} / \mathrm{s}-4}$ & 0,033 \\
\hline 5. & $\mathrm{~F}_{\mathrm{t} / \mathrm{s}-5}$ & 0,0297 \\
\hline 6. & $\mathrm{~F}_{\mathrm{t} / \mathrm{s}-6}$ & 0,212 \\
\hline 7. & $\mathrm{~F}_{\mathrm{t} / \mathrm{s}-7}$ & 0,0065 \\
\hline 8. & $\mathrm{~F}_{\mathrm{t} / \mathrm{s}-8}$ & 0,0234 \\
\hline 9. & $\mathrm{~F}_{\mathrm{t} / \mathrm{s}-9}$ & 0,126 \\
\hline \multicolumn{2}{|c|}{ Итого } \\
\hline
\end{tabular}

Источник: составлено автором 
внешней среды РИД. Привлечённая группа экспертов оценила показатели. Результаты оценки представлены в таблице 5

С учетом веса влияния и вектора влияния показателей мы получаем интегральную оценку факторов внешней среды (табл. 6).

Проводим распознавание интегрального показателя, факторы внешней среды со значением 71,7\% характеризует высокий потенциал коммерциализации.

После распознавания полученных интегральных показателей аккумулируем полученные значения в треугольнике потенциала коммерциализации РИД для финальной оценки рассчитанных показателей (рис. 2).

Данный треугольник отражает уровень коммерческого потенциала РИД с учетом минимальных значений по каждой группе показателей. Таким образом, можно заметить, что по группе показателей «факторы внешней среды» и «потенциал субъекта РИД» объект исследования имеет высокие показатели, что говорит о высоком потенциале коммерциализации, при этом, по группе показателей «внутренний потенциал РИД» полученное значение не превышает минимально допустимый уровень, соответственно, перед выводом рассматриваемого объекта на рынок, необходимо дополнительно усилить характеристики, относящиеся к РИД.

Вместе с треугольником потенциала коммерциализации РИД выстроим треугольник надежности результатов анализа потенциала коммерциализации РИД, который в свою очередь показывает уровень уверенности экспертов в полученном результате (рис. 3).

Исходя из полученных значений можно сделать вывод, что надежность полученных значений не вызывает сомнений, соответственно полученным данным в результате применения методики можно доверять, а предложенную методику необходимо применять при анализе РИД в высших учебных заведениях.

Таким образом, полученные при помощи нечетко-множественной модели результаты оценки потенциала коммерциализации разработки команды молодежного конструкторскотехнологического бюро Polytech Solar Team солнцемобиль SOL, доказывают практическую значимость предложенного способа оценки и актуальность в условиях постоянно повышающихся требований по внедрению разработанных в высших учебных заведениях инноваций в

Таблица 5. Оценка показателей, характеризующих степень влияния потенциала субъекта РИД на потенциал коммерциализации РИД

\begin{tabular}{|c|c|c|c|c|}
\hline № & \multicolumn{4}{|l|}{ Факторы внешней среды РИД } \\
\hline 1. & \multicolumn{4}{|l|}{ Экономическая ситуация в стране } \\
\hline 1.1 & ВВП на душу населения & $\mathrm{F}_{\mathrm{t} / \mathrm{e}-1}$ & 29181 & $\begin{array}{l}\text { Долл. } \\
\text { США }\end{array}$ \\
\hline 1.2 & Индекс производительности труда & $\mathrm{F}_{\mathrm{t} / \mathrm{e}-2}$ & 103 & $\%$ \\
\hline 1.3 & Доля высокотехнологичных и наукоемких отраслей экономики в ВВП & $\mathrm{F}_{\mathrm{t} / \mathrm{e}-3}$ & 21,3 & $\%$ \\
\hline 1.4 & Доля инвестиций в основной капитал в ВВП & $\mathrm{F}_{\mathrm{t} / \mathrm{e}-4}$ & 20,6 & $\%$ \\
\hline 2. & \multicolumn{4}{|l|}{ Уровень конкуренции на рынке } \\
\hline 2.1 & Коэффициент рыночной концентрации & $\mathrm{F}_{\mathrm{t} / \mathrm{e}-5}$ & 55 & $\%$ \\
\hline 2.2 & Индекс рыночной концентрации Херфиндаля-Хиршмана & $\mathrm{F}_{\mathrm{t} / \mathrm{e}-6}$ & 1539 & ед \\
\hline 3. & \multicolumn{4}{|l|}{ Уровень развития отрасли } \\
\hline 3.1 & Уровень инновационной активности организаций & $\mathrm{F}_{\mathrm{t} / \mathrm{e}-7}$ & 10,4 & $\%$ \\
\hline 3.2 & $\begin{array}{l}\text { Объем инновационных товаров, работ, услуг от общего объема } \\
\text { отгруженных товаров, выполненных работ, услуг }\end{array}$ & $\mathrm{F}_{\mathrm{t} / \mathrm{e}-8}$ & 5,3 & $\%$ \\
\hline 3.3 & $\begin{array}{l}\text { Количество приобретенных организациями новых технологий, } \\
\text { программных средств }\end{array}$ & $\mathrm{F}_{\mathrm{t} / \mathrm{e}-9}$ & 22678 & ед \\
\hline 4. & \multicolumn{4}{|l|}{ Государственная поддержка инноваций } \\
\hline 4.1 & $\begin{array}{l}\text { Финансирование науки из средств федерального бюджета к расходам } \\
\text { федерального бюджета }\end{array}$ & $\mathrm{F}_{\mathrm{t} / \mathrm{e}-10}$ & 2,77 & $\%$ \\
\hline 5. & \multicolumn{4}{|c|}{ Наличие связи с поставщиками и сбытовыми сетями } \\
\hline 5.1 & Достаточность поставщиков для создания РИД & $\mathrm{F}_{\mathrm{t} / \mathrm{e}-11}$ & 75 & $\%$ \\
\hline 5.2 & Достаточность объема закупаемых товаров, работ, услуг & $\mathrm{F}_{\mathrm{t} / \mathrm{e}-12}$ & 84 & $\%$ \\
\hline
\end{tabular}

Источник: составлено автором 
Таблица 6. Интегральная оценка факторов внешней среды

\begin{tabular}{|c|c|c|}
\hline o & Показатель & Значение \\
\hline 1. & $\mathrm{~F}_{\mathrm{t} / \mathrm{e}-1}$ & 0,024 \\
\hline 2. & $\mathrm{~F}_{\mathrm{t} / \mathrm{e}-2}$ & 0,01125 \\
\hline 3. & $\mathrm{~F}_{\mathrm{t} / \mathrm{e}-3}$ & 0,02 \\
\hline 4. & $\mathrm{~F}_{\mathrm{t} / \mathrm{e}-4}$ & 0,017 \\
\hline 5. & $\mathrm{~F}_{\mathrm{t} / \mathrm{e}-5}$ & 0,102 \\
\hline 6. & $\mathrm{~F}_{\mathrm{t} / \mathrm{e}-6}$ & 0,104 \\
\hline 7. & $\mathrm{~F}_{\mathrm{t} / \mathrm{e}-7}$ & 0,0548 \\
\hline 8. & $\mathrm{~F}_{\mathrm{t} / \mathrm{e}-8}$ & 0,1035 \\
\hline 9. & $\mathrm{~F}_{\mathrm{t} / \mathrm{e}-9}$ & 0,10217 \\
\hline 10. & $\mathrm{~F}_{\mathrm{t} / \mathrm{e}-9}$ & 0,0989 \\
\hline 11. & $\mathrm{~F}_{\mathrm{t} / \mathrm{e}-9}$ & 0,045 \\
\hline 12. & $\mathrm{~F}_{\mathrm{t} / \mathrm{e}-9}$ & 0,03375 \\
\hline \multicolumn{2}{|c|}{ Итого } & $\mathbf{7 1 , 7 \%}$ \\
\hline
\end{tabular}

Источник: составлено автором

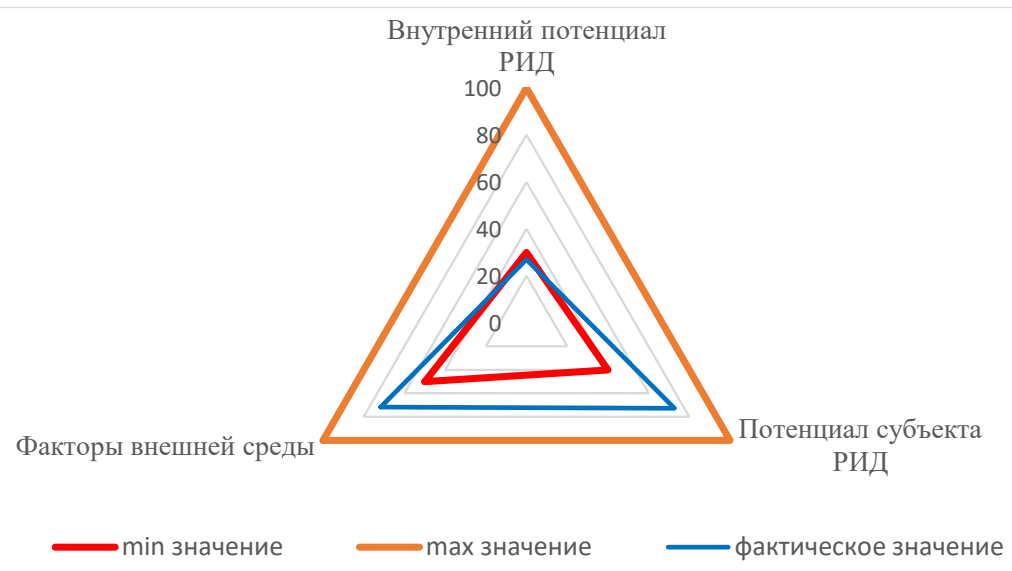

Рисунок 2. Треугольник потенциала коммерциализации РИД Источник: составлено автором

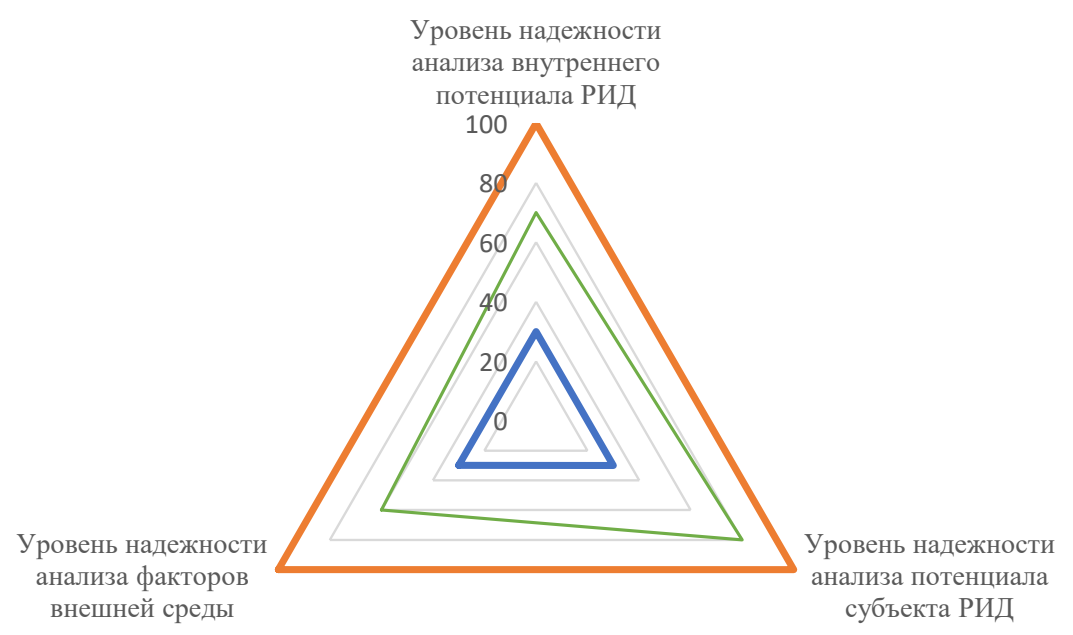

— $\min$ значение — —актическая надежность — 
реальный сектор экономики.

Рассмотренная нечетко-множественна модель позволяет оценить потенциал коммерциализации результата инновационной деятельности исходя из трех групп показателей: внутренний потенциал РИД, потенциал субъекта РИД и факторы внешней среды. Если с двумя последними группами факторов в рассмотренном примере проблем нет, то показатель внутреннего потенциала оказался незначителен. Это может быть связано в том числе и с тем, что у коллектива разработчиков недостаточно компетенций для разработки коммерчески успешного инновационного продукта [7,8]. В связи с этим и, учитывая количество информационных источников используемых для оповещения работников высшего учебного заведения о наличии заказа на исследование и сложности с коммуникациями между структурами высшего учебного заведения, необходимо разработать такую методику активизации инновационной деятельности в вузе, которая бы аккумулировала в себе все имеющиеся заказы на исследования и позволяла бы формировать исследовательские группы исходя из компетенций исследователей (рис. 4).

Процесс активизации инновационной деятельности в высшем учебном заведении можно условно разделить на четыре основных этапа.

1) Поиск и обработка заказов на исследования

На первом этапе происходит поиск заказов на исследования. Заказчики исследований могут быть как внешними, так и внутренними. Внешних заказчиков можно сегментировать на две основные группы: государственные предприятия и организации, такие как фонд Российский фонд фундаментальных исследований, российский научный фонд, фонд содействия инновациям, федеральные, отраслевые и региональные органы власти и т.д. и коммерческие организации, например, заказ на моделирование, исследование, разработку и т.д. Внутренними заказчиками могут служить: подразделения высшего учебного заведения и научные группы, индивидуальные исследователи, которым для реализации проекта или исследования необходим ученый с определенным набором компетенций.

2) Формирования пула сотрудников высшего учебного заведения занимающихся научноисследовательской деятельностью

На втором этапе создается единая информа- ционная система, которая будет содержать необходимую информацию о сотрудниках высшего учебного заведения, занимающихся исследовательской деятельностью [9,14].

При этом у каждого сотрудника должна быть отражена полная информация о его ключевых компетенциях, опыте исследовательской деятельности, участия в научных конкурсах и т.д.

3) Формирование исследовательских групп для решения конкретной исследовательской задачи

После того как найдены и проанализированы заказы на исследования и сформирован пул из профессорско-преподавательского состава, активно занимающегося исследованиями, применяется методика распределения профессорско-преподавательского состава под каждый конкретный заказ на исследование на основании своих компетенций [12]. В результате чего формируются исследовательские группы, обладающие необходимыми компетенциями, в виде профессорско-преподавательского состава и ресурсами высшего учебного заведения, такими как лаборатории, базы данных и т.д.

Вместе с тем на сформированную под конкретное исследование научную группу будет оказываться стимулирующее воздействие при помощи распределенной методики стимулирования инновационной деятельности (рис. 5).

Использовать предложенную распределенную методику предлагается следующим образом: необходимо определить перечень результатов инновационной деятельности, которые наиболее важны для высшего учебного заведения. Соответственно каждому полученному результату предшествует механизм конверсии ресурса высшего учебного заведения в результат $[7,8]$. Выделим восемь механизмов и три группы:

1. Материальные.

2. Нематериальные.

3. Административные.

Выделенные механизмы стимулирования имеют многоаспектный характер и варьируются не только от того какой необходим результат инновационной деятельности, но и от того, кто будет обеспечивать инновационную деятельность, т.е. от характеристик профессорскопреподавательского состава.

Наконец, каждому механизму стимулирования предшествуют ресурсы высшего учебного заведения, которые непосредственно будут влиять на инновационную деятельность сотруд- 


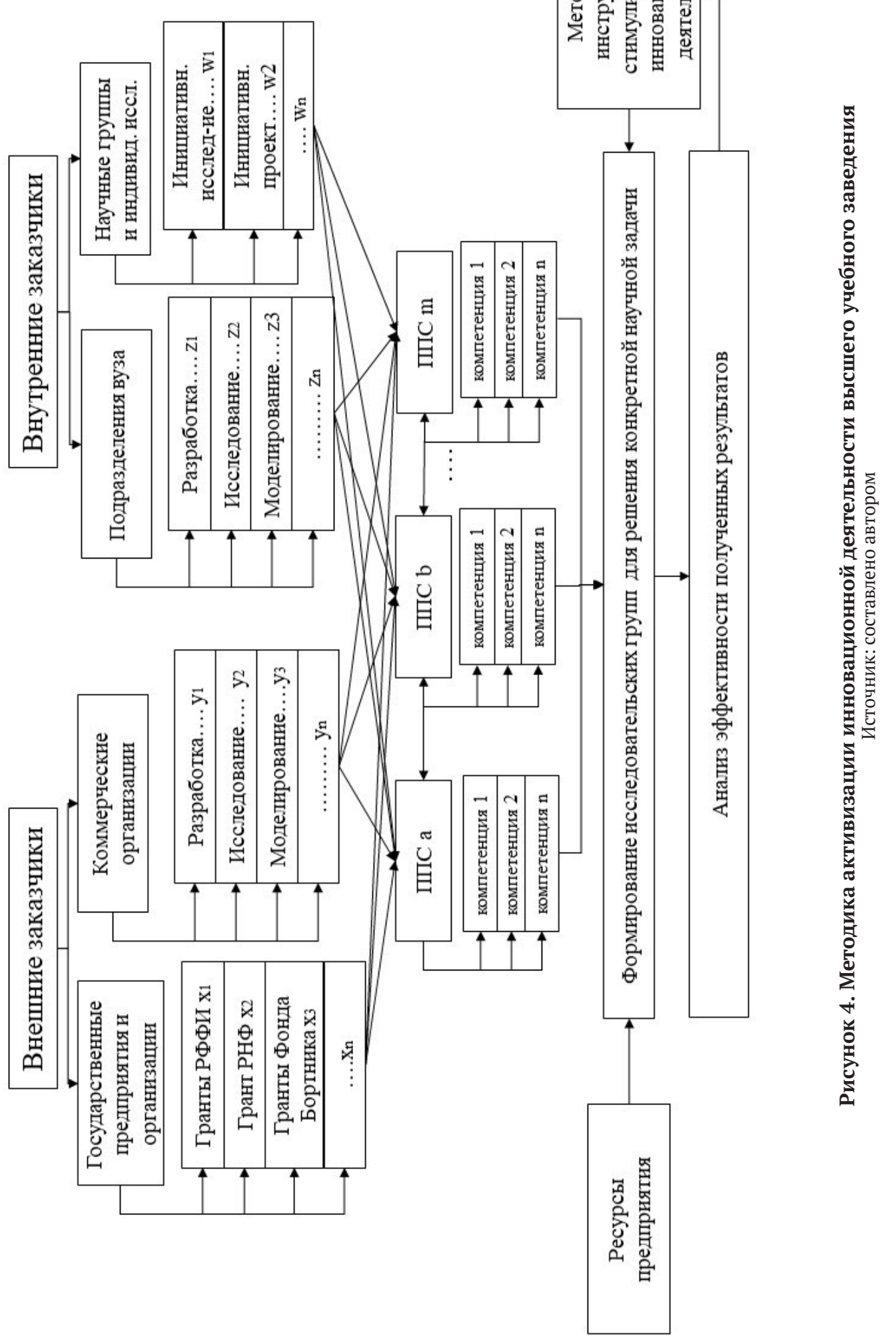




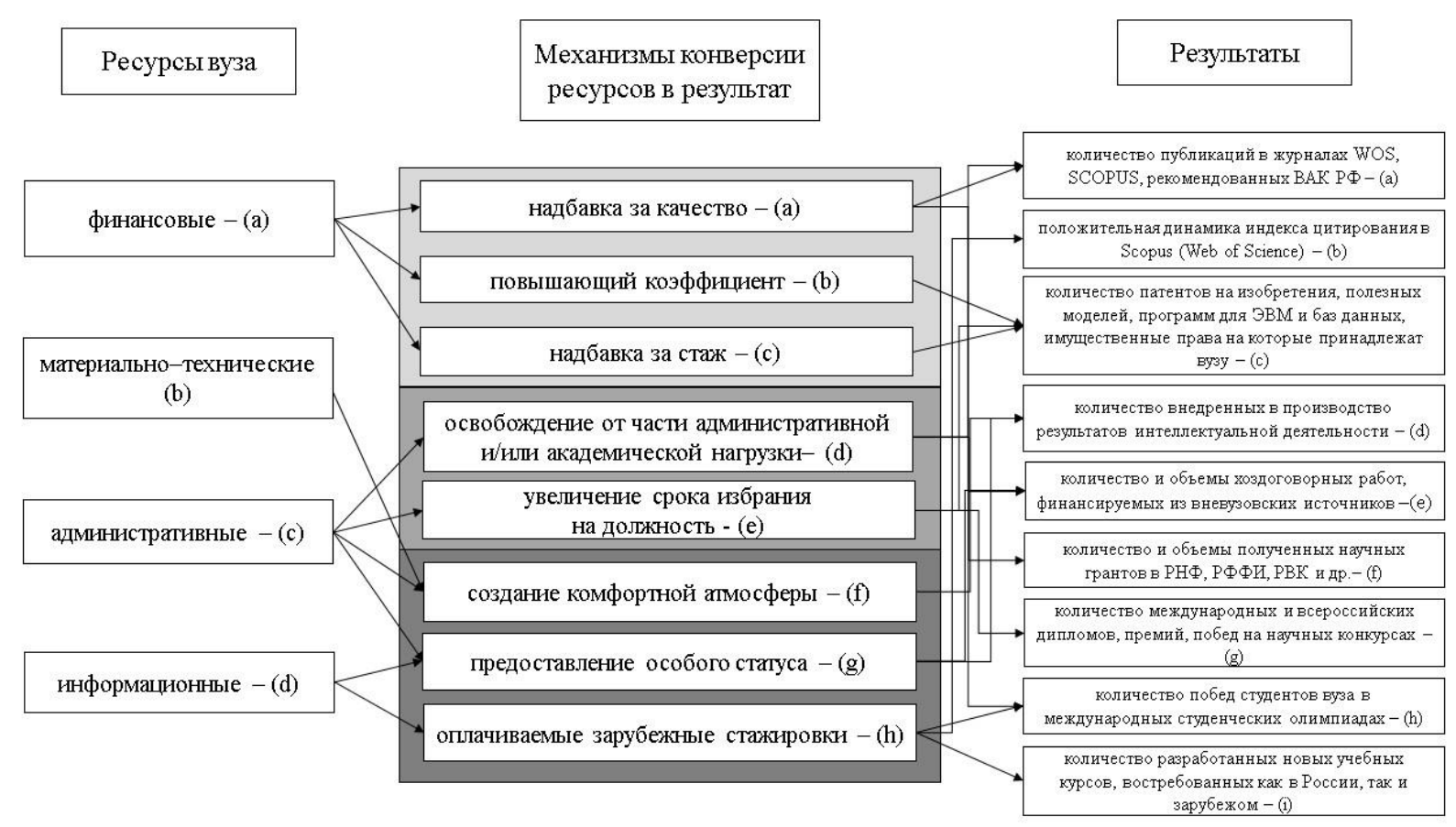

Рисунок 5. Распределенная методика стимулирования инновационной деятельности научно-исследовательского коллектива высшего учебного заведения

Источник: составлено автором

ников высшего учебного заведения. Например, для того чтобы получить результат «количество патентов на изобретения, полезных моделей, программ для ЭВМ и баз данных, имущественные права на которые принадлежат вузу» необходимо применить финансовые механизмы такие как «надбавка за качество», административные механизмы «освобождение от части административной и/или академической нагрузки», «увеличение срока избрания на должность» и нематериального механизма «предоставление особого статуса».

4) Анализ эффективности результата исследования

После того как исследование будет проведено необходимо провести анализ полученного результата на предмет его соответствия требованиям заказчика, а также анализ эффективности использования ресурсов и инструментов стимулирования.

Таким образом, в результате анализа существующих методов активизации инновационной деятельности была сформирована методика активизации инновационной деятельности, позволяющая при помощи единой информационной системы и методики распределения формировать такие исследовательские группы, которые обладают всеми необходимыми компетенциями для успешного выполнения исследования, при этом эффективно используя ресурсы высшего учебного заведения и инструменты стимулирования инновационной деятельности.

\section{Библиографический список}

1. Lyamin В. [и др.]. Methodology of Intellectual Property Objects Commercial Potential Evaluation// IOP Conference Series: Materials Science and Engineering. 2020. (940). С. 12072.

2. Lyamin В. [и др.]. Stimulating innovative activities in the university 2020.

3. Кобичева А. М., Калинина О. В., Родионов Д. Г. Университет в роли инновационной корпорации // Российский экономический интернет-журнал. 2019. № 4. С. 73.

4. Курбатова М. В., Левин С.Н. Эффективный контракт в системе высшего образования РФ: теоретические подходы и особенности институционального проектирования // Journal of institutional studies (Журнал институциональных исследований). 2013. № 1 (5). 
5. Лебедев О. Т., Родионов Д. Г., Мокеева Т.В. Построение организационно-экономического механизма управления жизненным циклом фундаментальных научно-технологических инноваций // Экономика и предпринимательство. 2019. № 5. С. 701-709.

6. Лебедев О. Т., РодионовД.Г., Мокеева Т.В. Уточнение структуры жизненного цикла фундаментальных научно-технологических инноваций // Вестник Алтайской академии экономики и права. 2019. № 8. С. 7178.

7. Лямин Б. М. Моттаева А.Б. Оценка потенциала коммерциализации результатов инновационной деятельности в высшем учебном заведении // Экономические науки. 2020. (191). С. 110-115.

8. Лямин Б. М. Моттаева А.Б. Анализ методических подходов к стимулированию инновационной деятельности в высшем учебном заведении // Экономические науки. 2020. (191). С. 105-109.

9. Назарова И.Б. Контракт университета с преподавателем: права и обязанности // Образовательные технологии (г. Москва). 2014. № 3.

10. Погребова О. А., Конников Е.А., Юлдашева О. У. Нечетко-множественная модель оценки индекса развития устойчивого маркетинга компании Федеральное государственное автономное образовательное учреждение высшего ..., 2017.С. 522-525.

11. Пушкарёв Ю. В., Латуха О.А. Оценка эффективности деятельности современного университета как инновационного вуза // Science for Education Today. 2012. № 1 (5).

12. Седякина А. А., Конников Е. А. Методика оценки совместимости научно-исследовательского коллектива // Экономические науки. 2020. № 188. С. 77-87.

13. Симоненко E. С. Оценка инновационного потенциала вуза на основе разработки комплексной системы показателей и индикаторов // Инновационная экономика: перспективы развития и совершенствования. 2013. № 3 (3).

14. Яковлева Т. В., Суржикова А. В., Петрова М. А. Малые инновационные фирмы вуза: формирование, оценка эффективности и привлечение финансирования // Universum: Вестник герценовского университета. 2012. № 3. 